\title{
A Novel PWM Modulation and Hybrid Control Scheme for Grid-connected Unipolar Inverters
}

\author{
Zhongwei Guo ${ }^{1,2}$ \\ ${ }^{1}$ Shindengen Electric Mfg. Co., Ltd. \\ Hanno, Saitama, 357-8585 Japan
}

\author{
Fujio Kurokawa ${ }^{2}$ \\ ${ }^{2}$ Graduate School of Science and Tecnology, \\ Nagasaki University \\ Nagasaki, 852-8521 Japan
}

\begin{abstract}
The purpose of this paper is to provide low cost, high power quality and high efficiency solutions for gridconnected inverters. Compared with bipolar switched inverters, unipolar switched inverters have the advantages of higher efficiency due to reduced switching frequency and low iron losses of inductor in output filter. However, unipolar inverters produce large harmonic distortion due to the deadtime effects. To address this issue and achieve higher efficiency, a new PWM modulation and a hybrid current control scheme is proposed.
\end{abstract}

Firstly, according to the polarity of current reference, in each leg, the gate drive signal of positive or negative switch is removed, and the dead-time insertion is eliminated. With this modulation method, the inverter circuit operations are divided into six operation modes, and their mathematical models are derived.

According to this mathematical model, a hybrid control scheme is proposed that consists of a PI controller and an open-loop controller. The PI controller operates in the linear areas, and the open-loop controller operates in the nonlinear areas. Several control rules are designed to realize smooth transition between different control modes.

With this control scheme, firstly, the influence of dead-time can be eliminated, and the harmonic distortion can be greatly reduced. Without the influence of switching dead-time, the dclink voltage can be minimized that will contribute to reduced switching losses and smaller ripple current.

The proposed control scheme is verified with simulation and experimental results. The experimental test is implemented in a $10 \mathrm{~kW}$ single-phase grid-connected inverter that uses a DSP controller TMS320F2808. The reductions of conversion losses, low harmonic distortion and low ripple current are all confirmed in the experimental system. The comparisons between the conventional control scheme and the proposed scheme are presented in this paper.

\section{INTRODUCTION}

Renewable energy generation system usually uses a gridconnected inverter to interface with utility grid. To promote widespread applications, low harmonic distortion, more efficient and low-cost grid-connected inverters are required.

Various circuit topologies have been proposed for gridconnected inverters [1], two-stage inverter circuit is an usually used approach that has a dc-dc converter to boost a low dc voltage to a proper dc-link voltage required for inverter operations. A high dc-link voltage results in large switching losses [2] and large ripple current. Due to the large ripple current, inductor iron losses increases [3], and a larger dc-link electrolytic capacitor is required because of the high operation voltage. The minimization of dc-link voltage will improve the conversion efficiency and contribute to a reduced size. The dead-time necessary in PWM inverters results in output harmonic distortion, and deteriorates the utilization of dc link voltage. To maintain the output quality, a higher dc-link voltage is required. Many dead-time compensation methods have been proposed for motor drive inverters [4]-[6], usually it uses the current polarity to compensate the dead-time effect. However, for inverter with LC filter, especially, when a small inductor is applied in the output filter, it may deteriorate the output on the contrary, to address this problem, for bipolar switched inverters, a sliding mode controller is proposed [7][8].

Compared with bipolar switched inverters, unipolar switched inverters have the advantages of higher efficiency due to the reduced switching frequency [9] and low iron loss of inductor in output filter [3]. However, unipolar inverters output large harmonic distortion due to the dead-time effects [9]. For low cost solutions, the manufactures prefer a small inductor in the output filter, in this case, the methods proposed in [4]-[6] will not produce satisfied improvements, and because the operation characteristics varies greatly due to the output power level and the output power factor, methods shown in [7][8] is not suitable for the unipolar inverters.

In this paper, to provide high power quality and high efficiency solutions for grid-connected inverters, a novel PWM modulation and hybrid current control scheme is proposed.

To eliminate the influence of switching dead-time, according to the polarity of current reference, the gate drive signal of positive or negative switch is removed and deadtime insertion is eliminated. With this modulation method, the inverter operation of low current output areas becomes nonlinear operations, and conventional control method can not provide satisfied results. By analyzing the behaviors of this modulation method, the inverter operations are divided into six operation modes, and a complete mathematical model is developed. According to this mathematical model, 
an open-loop controller is proposed to operate in the nonlinear areas, and a conventional PI controller is applied in the linear areas. Several control rules are designed to realize smooth transition between different control modes.

With this control strategy, the dead-time insertion is eliminated, without the influence of switching dead-time, output harmonic distortion can be greatly reduced. The duty ratio of truly $100 \%$ can be carried out that will maximize the utilization of dc-link voltage. With a low dc-link voltage, the switching losses can be reduced and the switching frequency inductor ripple current in output filter decreases that will also contribute to a small iron losses.

The validation of the proposed control scheme is verified by simulation and experimental results. In the experimental system, compared with the conventional control scheme, an improvement of $0.44 \%$ European efficiency has been obtained, the total harmonic distortion is reduced to about $1 / 6-1 / 3$ of the conventional one, and the ripple currents of inductor in LC filter are reduced by about $20 \%$.

\section{INVERTER CIRCUIT CONFIGURATIONS}

\section{A. Inverter Circuit Configurations}

Figure 1 shows the inverter circuit configuration. It consists of a high-frequency isolated $\mathrm{dc} / \mathrm{dc}$ converter, a dclink capacitor, a voltage source inverter, and an LC output filter. In this figure, $V_{P V}$ is the PV input voltage, $V_{d c}$ is the dc-link voltage, $V_{i n v}$ is the inverter output pulse voltage, $L_{f} / C_{f}$ are the inductor and capacitor of LC filter, and $L_{S} / R_{S}$ represents the inductance and the resistance between the inverter and the utility grid. Using unipolar modulation method, the pulse frequency of inverter circuit output doubles the switching frequency, therefore switching losses can be reduced. However, for unipolar inverters with a small inductor in output filter, because the operation characteristics varies due to the output power level and power factor, the dead-time problem becomes a difficult issue.

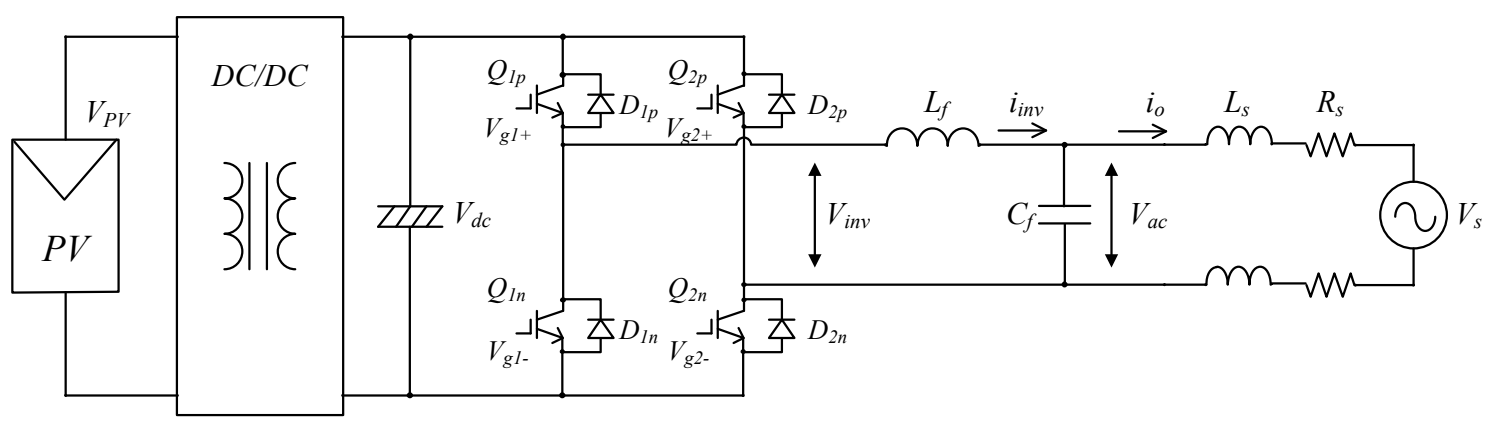

Fig. 1. Circuit configurations.

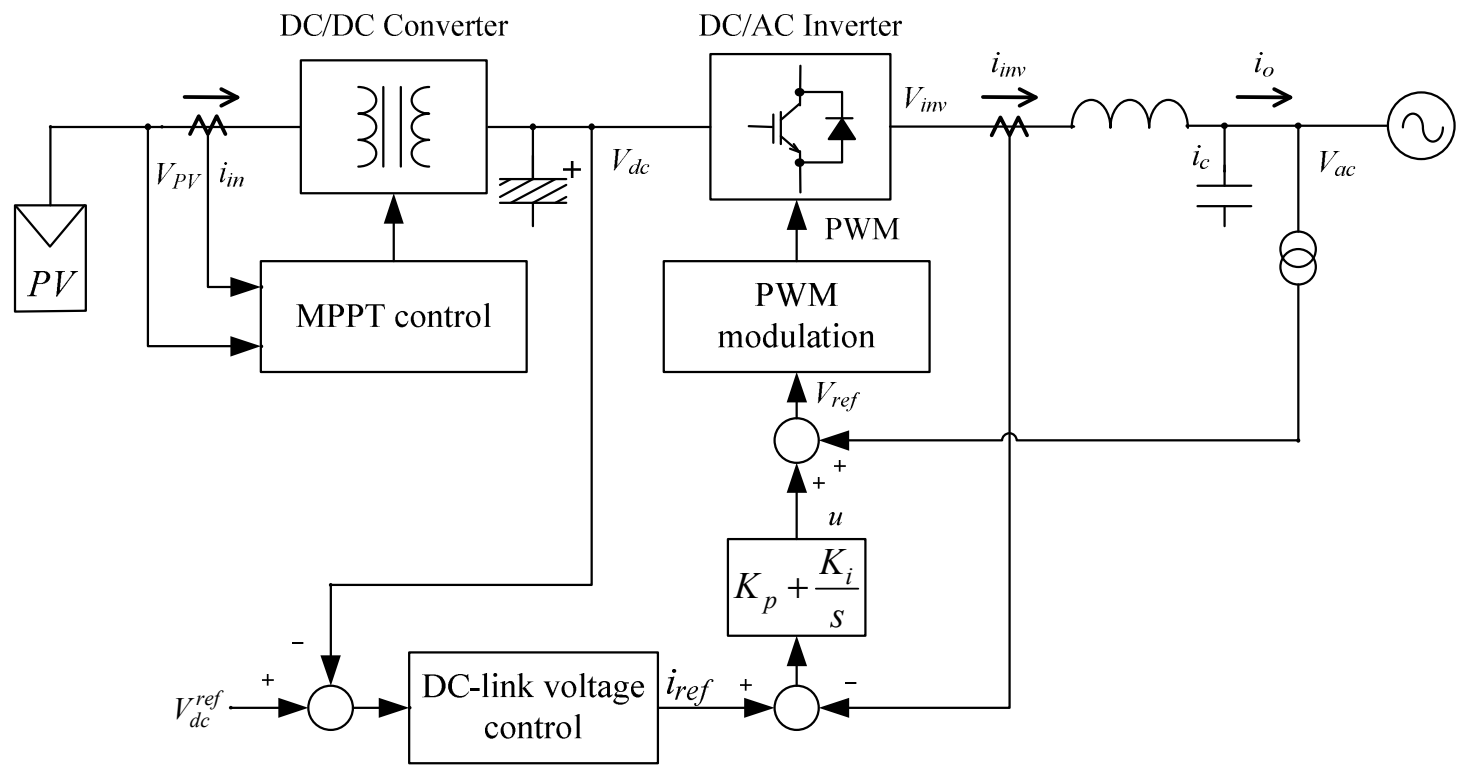

Fig. 2. Conventional control block diagram. 


\section{B. Problems of Conventional Current Control}

Figure 2 shows the inverter control configuration. The $\mathrm{dc} / \mathrm{dc}$ converter realizes the high frequency isolation and MPPT control. The dc-link voltage is regulated by inverter controller. A PI controller realizes the inverter current control, and the AC voltage is used as a feed-forward signal. Finally, the duty ratio of the positive switch is obtained by Eq. (1), the gate drive signal of the negative switch is the complementary output of the positive switch. To prevent the short circuit of dc-link voltage, a dead-time is inserted between the commutations.

$$
D=\left(V_{r e f} / V_{d c}+1\right) / 2=\left(\left(u+V_{a c}\right) / V_{d c}+1\right) / 2
$$

where $V_{\text {ref }}$ is the inverter voltage reference, $V_{d c}$ is the dclink voltage, $\mathrm{u}$ is the output of the PI current controller, and $V_{a c}$ is the utility grid voltage, which is measured at the $\mathrm{AC}$ terminal. Since only some wires and EMI filter exist between the AC terminal and capacitor circuit, $V_{a c}$ is assumed to the same with the capacitor voltage.

Because this paper is to propose a novel PWM modulation method and a hybrid current control scheme, the detail of dc-dc converter and the dc-link voltage control are omitted in this paper.

Figure 3 shows the experimental waveforms of conventional control at the condition of $V_{d c}=360 \mathrm{~V}$. Due to

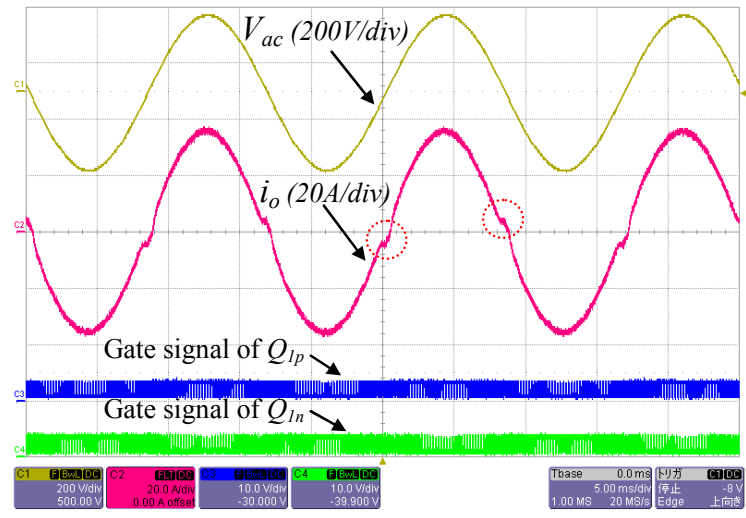

Fig. 3. Experimental waveforms of conventional control.

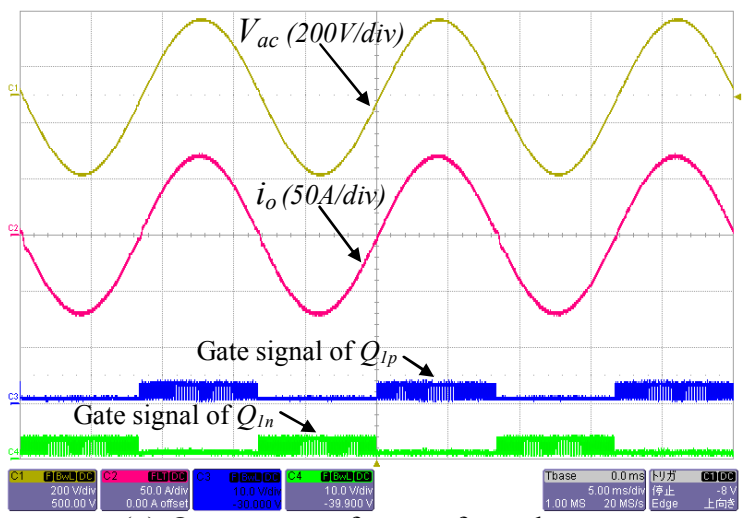

(a) Output waveforms of rated power. the dead-time effects, near the zero crossing point, significant current distortions can be observed. With the conventional PWM modulation method, because the deadtime is inserted in the gate signals, the maximum duty cycle becomes dead-time short compared with the ideal switch condition. With a similar analysis as shown in [7], the deadtime error voltage can be depicted as Eq. (2), in the experimental system, the dead-time is set to be $3 \mu \mathrm{s}$, and the dc-link voltage should be $21.6 \mathrm{~V}$ higher compared with the ideal switch condition.

$$
\Delta V=\frac{T_{d}}{T_{c}} \cdot 2 \cdot V_{d c}
$$

\section{PROPOSED PWM CONTROL AND ITS ANALYSIS}

\section{A. The proposed PWM modulation control}

Figure 4 shows the proposed PWM modulation. When the polarity of current reference $\left(i_{\text {ref }}\right)$ is positive, gate signals of $Q_{1 n}$ and $Q_{2 p}$ are removed. Otherwise, gate signals of $Q_{1 p}$ and $Q_{2 n}$ are removed. Using this modulation control method, at the high output condition, a low distortion output can be achieved. However, at a low power output condition, the output current presents large distortion. Figure 5(a) shows the output waveforms at the rated power condition, and figure 5 (b) shows the output at $20 \%$ rated power condition.

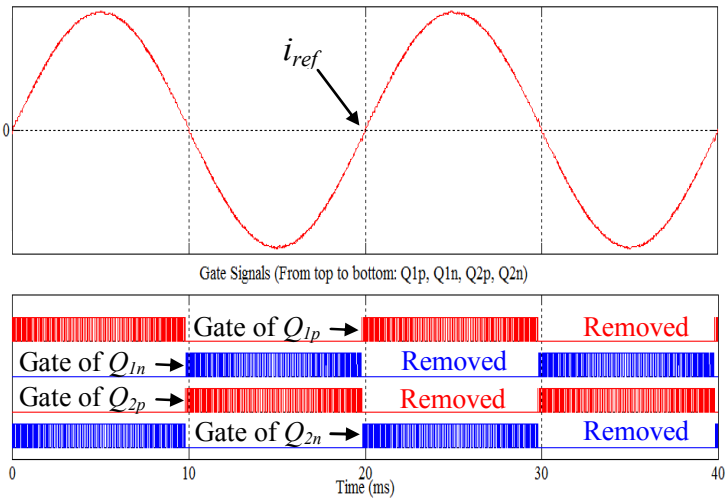

Fig. 4. The proposed PWM modulation method.

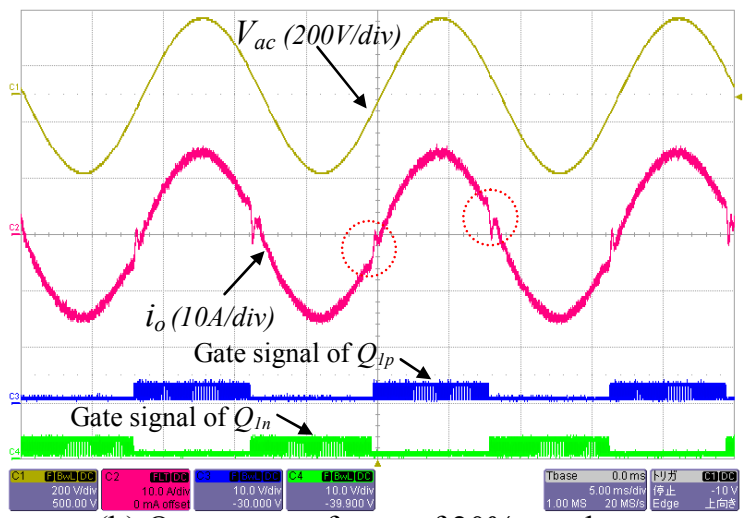

(b) Output waveforms of $20 \%$ rated power.

Fig. 5. Experimental waveforms of proposed PWM modulation method with conventional PI control. 


\section{B. Mathematical model of the proposed PWM control}

To solve the above problems, by analyzing the PWM behaviors, a mathematical model is developed to describe the operation characteristics of the proposed PWM modulation control. In this model, the PWM operations are divided into six operation modes according to the output current (inductor current) and the $\mathrm{AC}$ voltage.

\section{1) Operation mode $1\left(\bar{i}_{\text {inv }}>i_{r} / 2\right)$}

Figure 6 shows the PWM operation waveforms of mode 1 at the condition of $V_{\text {ref }}>0$. Here, $V_{\text {ref }}$ is the modulation voltage reference of IGBT switches, the duty ratio is calculated according to Eq. (1), $V_{d c}$ is the dc-link voltage, $i_{i n v}$ is the inductor current in LC filter, $i_{r}$ represents the switching ripple current, $\bar{i}_{i n v}$ is the average current during a carrier period, $T_{c}$ is the carrier period, and $V_{g l+} / V_{g I_{-}} / V_{g 2+} / V_{g 2-}$ are the IGBT gate signals of inverter circuit.

In Fig. 6, during the switching cycle, the current polarity maintains positive, the time duration $T_{p}$ can be expressed as Eq. (3), and equation (4) illustrates the inductor switching ripple current.

$$
\begin{aligned}
& T p=\left\{\frac{T_{c}}{2} \cdot\left(1+\frac{V_{r e f}}{V_{d c}}\right)-\frac{T_{c}}{2} \cdot\left(1-\frac{V_{r e f}}{V_{d c}}\right)\right\} \cdot \frac{1}{2}=\frac{V_{r e f}}{V_{d c}} \cdot \frac{T_{c}}{2} \\
& i_{r}=T_{p} \cdot\left(V_{d c}-V_{a c}\right) \cdot \frac{1}{L_{f}}=\frac{V_{r e f}}{V_{d c}} \cdot \frac{T_{c}}{2} \cdot\left(V_{d c}-V_{a c}\right) \cdot \frac{1}{L_{f}}
\end{aligned}
$$

In this operation mode, because $i_{\text {ref }}>0$, the gate signals of $V_{g I_{-}}$and $V_{g 2+}$ are removed. In this case, after $V_{g 1^{+}}$turns off, diode $D_{2 n}$ conducts to realize the switching operation. Ignoring the switch drop voltage $\left(V_{f}\right.$ of the free-wheeling diode, and $V_{c e}$ saturation voltage), the average output voltage of $V_{i n v}$ can be expressed as Eq. (5), without the influence of switching dead-time, ideal switch operations can be obtained.

$$
\bar{V}_{i n v}=\frac{T_{p} \cdot 2 \cdot V_{d c}}{T_{c}}=\frac{V_{r e f}}{V_{d c}} \cdot \frac{T_{c}}{2} \cdot \frac{2 \cdot V_{d c}}{T_{c}}=V_{r e f}
$$

From Eq. (5), the relation between the voltage reference and the output current (inductor current) can be obtained as Eq. (6).

$$
i_{i n v}=\left(V_{r e f}-V_{a c}\right) \cdot \frac{1}{s \cdot L_{f}}
$$

where $s$ is the laplace operator.

At the condition of $V_{\text {ref }}<0$, through a similar analysis, the ideal switch operation characteristics can also be confirmed, but the switching ripple current becomes Eq. (7).

$$
i_{r}=-\frac{V_{r e f}}{V_{d c}} \cdot \frac{T_{c}}{2} \cdot\left(V_{d c}-V_{a c}\right) \cdot \frac{1}{L_{f}}
$$

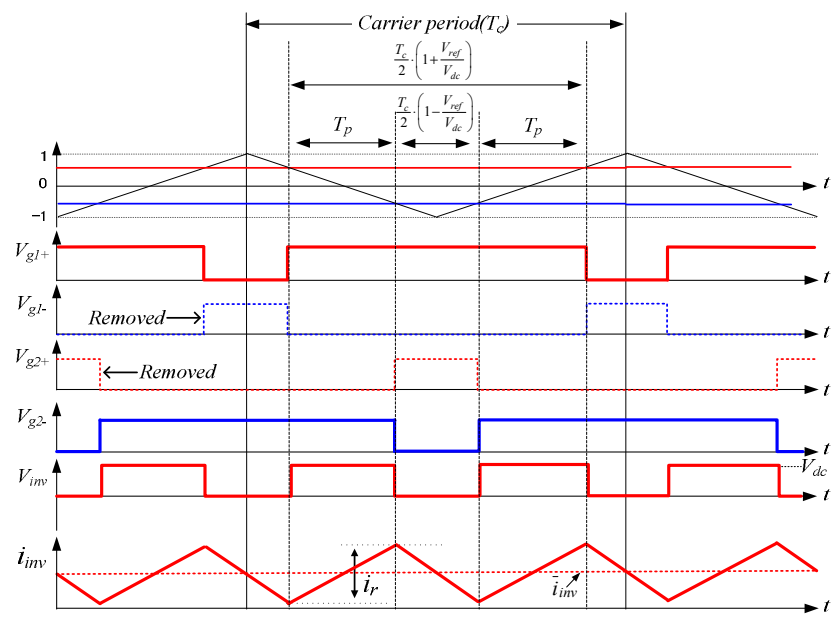

Fig. 6. PWM operation waveforms of mode 1 at the condition of $V_{\text {ref }}>0$.

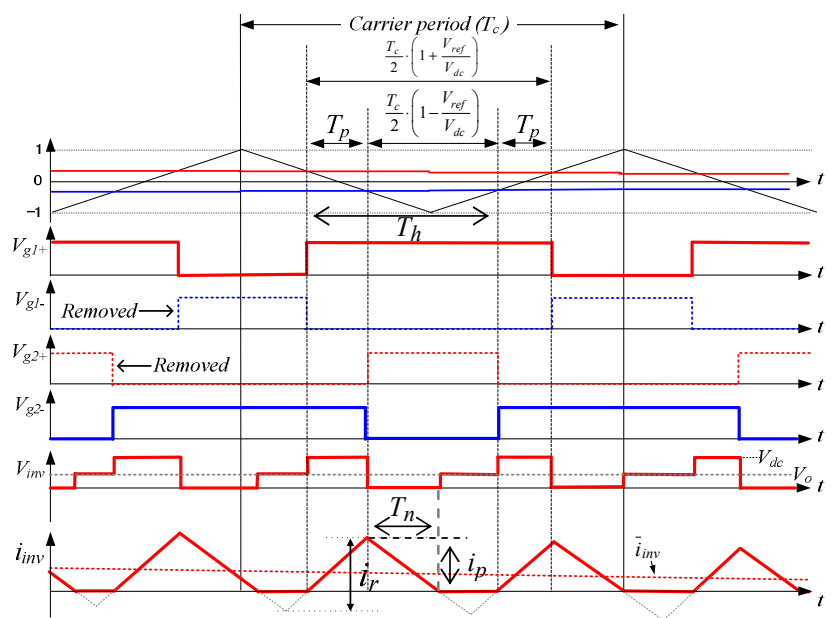

Fig. 7. PWM operation waveforms of mode 2.

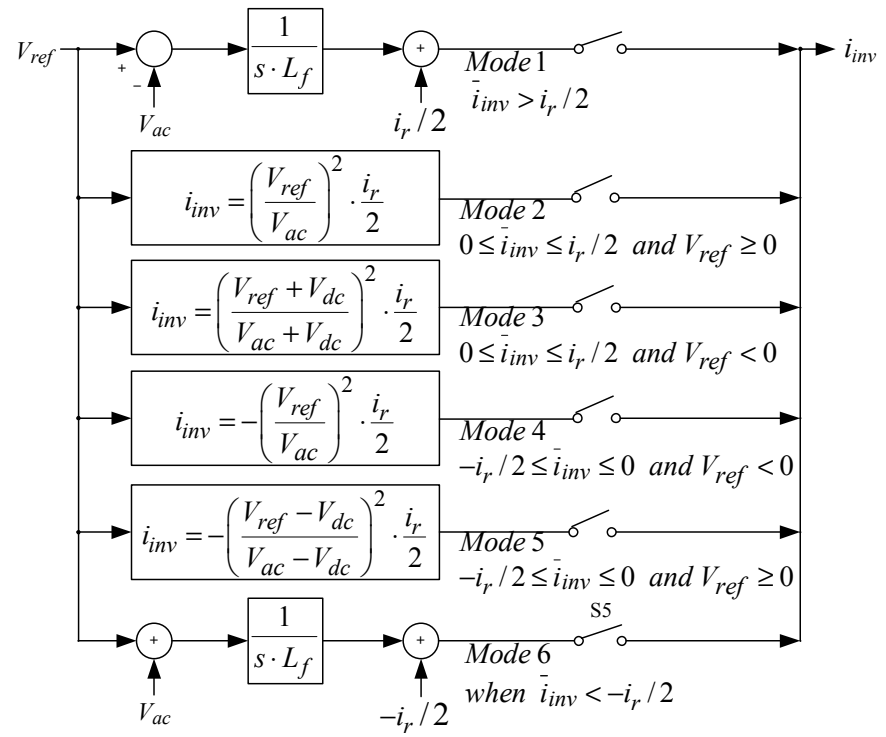

Fig. 8. Mathematical model of proposed PWM modulation. 
2) Operation mode $2\left(0 \leq i_{i n v} \leq i_{r} / 2\right.$ and $\left.V_{a c} \geq 0\right)$

Figure 7 shows the PWM operation waveforms of mode 2. By utilizing the conventional PWM modulation control and assuming that the IGBT is an ideal switch, the inductor current $\left(i_{\text {inv }}\right)$ waveform maintains the triangle appearance, on the positive side, the red line, on the negative side, the dotted line. The switching ripple current can be expressed as the same with mode 1 as shown in Eq. (4). However, with the proposed PWM modulation control, the phenomenon of zero-clamping occurs, only the positive current can be produced (the red line).

According to Fig. 7, the average current of period $T_{h}$ can be expressed as Eq. (8).

$$
\bar{i}_{i n v}=\frac{\left(T_{p}+T_{n}\right)}{T_{h}} \cdot \frac{i_{p}}{2}
$$

where,

$$
\begin{aligned}
& T_{h}=\frac{T_{c}}{2} \\
& T_{p}=\frac{V_{r e f}}{V_{d c}} \cdot \frac{T_{c}}{2} \\
& T_{p}+T_{n}=T_{p}+\frac{T_{p} \cdot\left(V_{d c}-V_{a c}\right)}{V_{a c}}=T_{p} \cdot \frac{V_{d c}}{V_{a c}} \\
& i_{p}=\frac{V_{r e f}}{V_{d c}} \cdot \frac{T_{c}}{2} \cdot\left(V_{d c}-V_{a c}\right) \cdot \frac{1}{L_{f}}
\end{aligned}
$$

from Eq. (8)-(12), equation (13) can be derived.

$$
\bar{i}_{i n v}=\left(\frac{V_{r e f}}{V_{a c}}\right)^{2} \cdot \frac{i_{r}}{2}
$$

where $i_{r}=-\frac{V_{a c}}{V_{d c}} \cdot \frac{T_{c}}{2} \cdot\left(V_{d c}-V_{a c}\right) \cdot \frac{1}{L_{f}}$

After analyzing all of the operation modes, an overall mathematical model are achieved as shown in Fig. 8.

\section{HyBrid CURRENT CONTROL SCHEME}

According to the developed mathematical model of the proposed PWM modulation, a hybrid current control scheme is proposed. Figure 9 shows the configurations of the proposed hybrid current controller. It consists of a PI controller and an open-loop controller. The PI controller operates in the linear areas (mode 1 and 6), and the openloop controller operates in the nonlinear areas (mode 2 to mode 5). Several control rules are used to realize smooth transition between different control modes.

The PI controller is designed with a conventional method, and the open-loop controller is designed basing on the equations shown in the mathematical model. Actually, the control equations are the reverse transformations of equations in the mathematical model.

Instead of the reference voltage $\left(V_{r e f}\right)$, AC voltage measured at the $\mathrm{AC}$ terminals is used to calculate the inductor ripple current $\left(i_{r}\right)$.

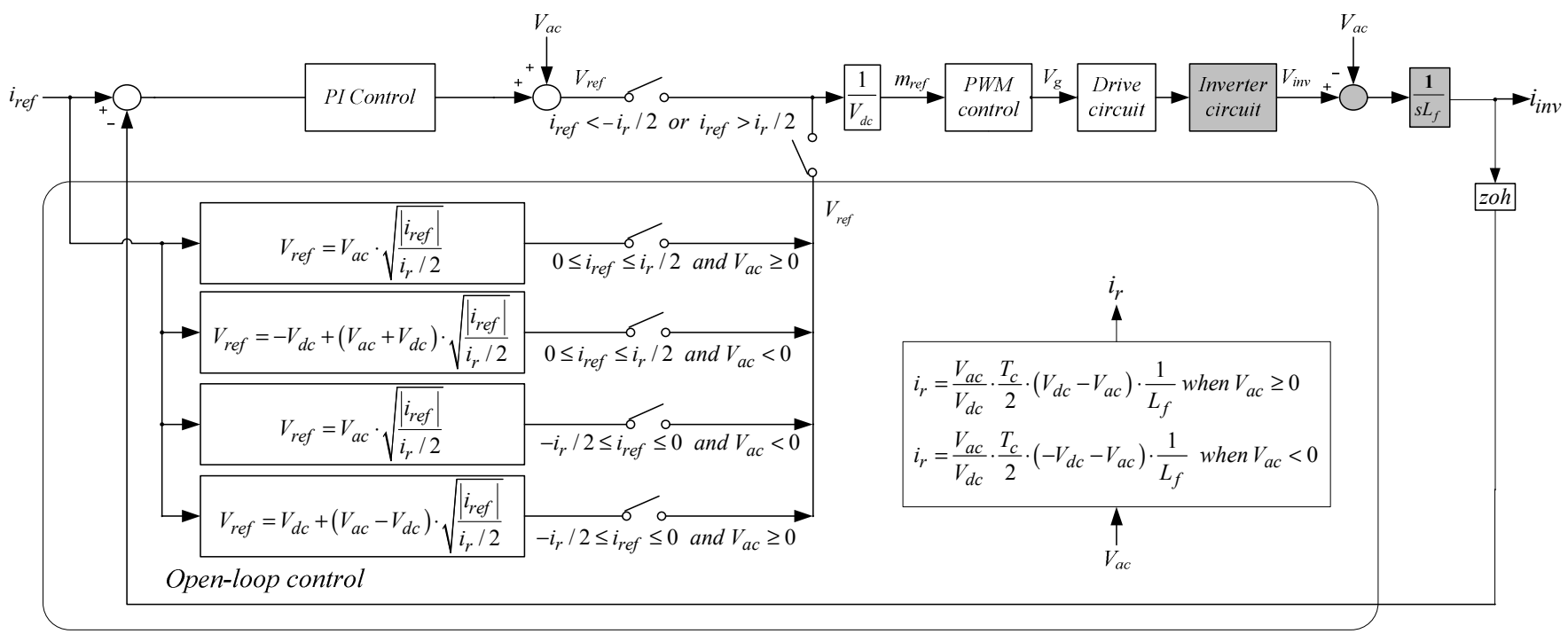

Fig. 9. Proposed hybrid current control scheme. 


\section{SimUlation VERIFICATION}

The proposed PWM modulation and current control scheme have been simulated with SimPower Systems toolbox of Matlab/Simulink software. Table I presents the system parameters of the grid-connected inverter utilized to obtain the simulation and experimental results. The comparisons between the conventional PI controller and the proposed hybrid controller are presented in this section.

Figure 10 shows the comparison at the rated power, and figure 11 shows the comparison at low power output conditions. Compared with the results of the conventional controller shown in Fig. 10(a) and 11(a), very low distortion current outputs are achieved in Fig. 10(b) and 11(b).

Figure 12 shows the comparisons of total harmonic distortion (THD) with variations of output current. The proposed PWM modulation with conventional PI current control is also used for comparison. The harmonic distortion is improved to about $1 / 6-1 / 3$ of the conventional, and the results are insensitive to variations of output current. With the proposed PWM modulation control and the conventional PI current control, although the THD can be improved at the large current output conditions, the output distorts greatly at the low output condition.

TABLE I. SYSTEM PARAMETERS

\begin{tabular}{|c|c|c|c|}
\hline Utility grid & $200 \mathrm{~V} / 50 \mathrm{~Hz}$ & Carrier frequency & $10 \mathrm{kHz}$ \\
\hline DC link voltage & $360 \mathrm{~V} / 320 \mathrm{~V}$ & Sampling Frequency & $20 \mathrm{kHz}$ \\
\hline Rated power & $10 \mathrm{~kW}$ & Inductor of LC filter & $0.66 \mathrm{mH}$ \\
\hline Dead-time & $3 \mu \mathrm{s}$ & Capacitor of LC filter & $24 \mu \mathrm{F}$ \\
\hline & \multicolumn{3}{|c|}{ Output curent(A) } \\
\hline
\end{tabular}

(a) Conventional PI control Fig. 10. Output current and gate drive

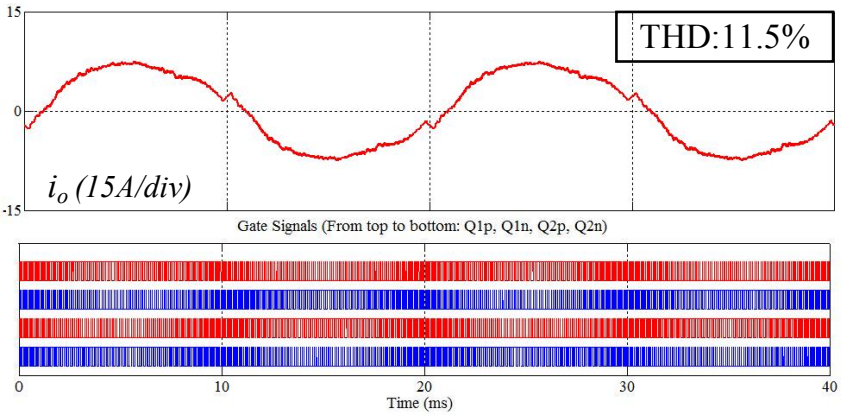

(a) Conventional PI control

\section{EXPERIMENTAL VERIFICATION}

The proposed control scheme has been experimentally tested in a single-phase $10 \mathrm{~kW}$ grid-connected inverter shown in Fig. 1. The controller is implemented with a digital signal processor TMS320F2808. The system parameters are the same with the simulation parameters as shown in Table I.

The comparison between the conventional method and the proposed are implemented with the same circuit setup including the measuring instrument. The conventional scheme and the proposed scheme are implemented in the same program, and the control method can be selected through an external command. Since the ambient temperature and the internal temperature rise have some influence on the conversion efficiency, in this paper,

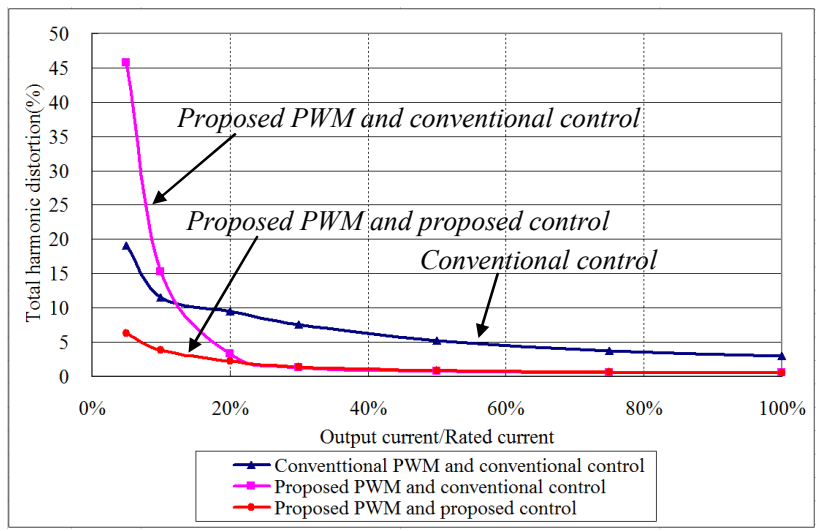

Fig. 12 Total harmonic distortion.

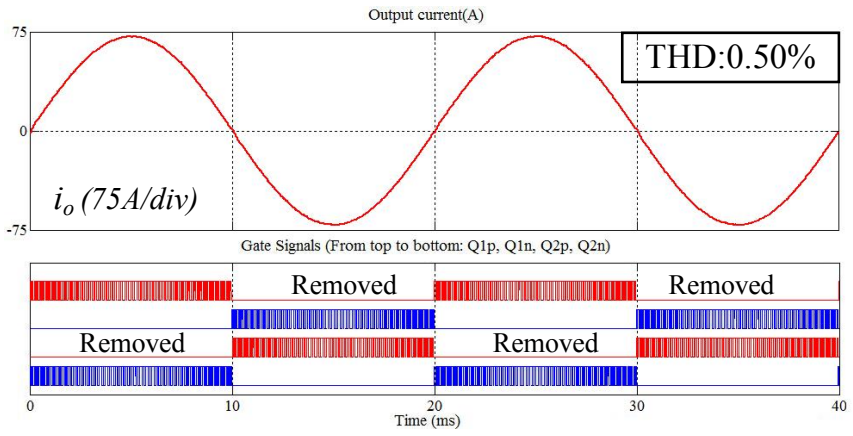

(b) Proposed hybrid control

rive signal waveforms (Rated power).

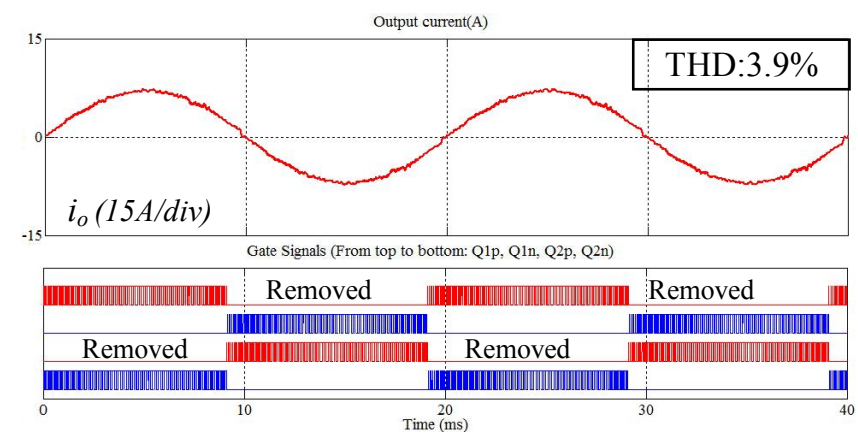

(b) Proposed hybrid control

Fig. 11. Output current and gate drive signal waveforms (10\% of rated power). 
efficiency data is achieved at nearly the same ambient temperature and after the internal temperature rise has reached a steady state.

Figure 13 shows the operation waveforms of the proposed control method. Figure 13(a) is the waveforms at the rated power condition, and figure 13(b) shows the waveforms at a low power output condition. Low distortion outputs are realized, and the results are insensitive to variations of output power. $\mathrm{V}_{\mathrm{dc}}=286 \mathrm{~V}$, even at the condition of lower limit of dc-link voltage, low distortion can also be achieved. Because $286 \mathrm{~V}$ is very near to the peak voltage of the utility grid, it means that the dc-link voltage can be fully utilized.

Figure 15 is the measured THD results. The total harmonic distortion decreases to about $1 / 6-1 / 3$ of the conventional, and the improvement is effective in all of the output range.

Figure 16 shows the inductor current comparison. By analyzing the measured waveform data with MATLAB/ Simulink software, the RMS value of the switching ripple current is achieved. The comparison results are shown in Fig. 17. The ripple current is reduced by about $20 \%$ according to

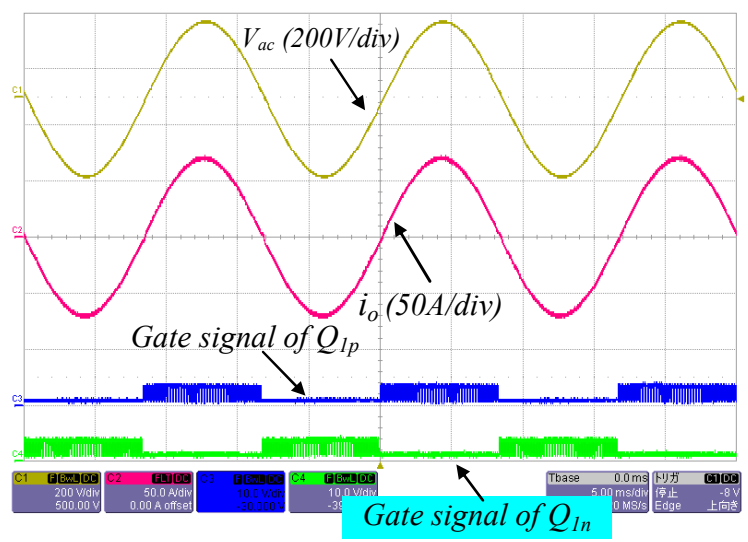

(a) Experimental waveforms. New320V10kW
Figure 14 shows the output waveforms at the condition of

the experimental results.

Figure 18 shows the efficiency improvement and Figure 19 shows the influence of dc-link voltage. Since the improvement is more effective at the low power output condition, through calculation using Eq. (15), an improvement of $0.44 \%$ European efficiency can be achieved.

$\eta_{\text {euro }}=0.03 \cdot \eta_{5}+0.06 \cdot \eta_{10}+0.13 \cdot \eta_{20}+0.1 \cdot \eta_{30}+0.48 \cdot \eta_{50}+0.2 \cdot \eta_{100}$

\section{CONCLUSIONS AND FUTURE WORK}

For grid-connected unipolar switched inverters, a novel PWM modulation and a hybrid current control scheme are proposed. With this PWM modulation method, the gate signals of the positive side switch or the negative side switch are removed. Without the influence of switching dead-time, the utilization of dc-link voltage can be maximized. Furthermore, to realize high power quality output, the mathematical model of the PWM modulation scheme is developed, according this mathematical model, a hybrid current control scheme is proposed. The proposed current control scheme consists of a PI controller and an open loop controller. The PI controller operates in the linear areas and the open loop controller operates at the nonlinear areas. Several control rules are designed to realize smooth

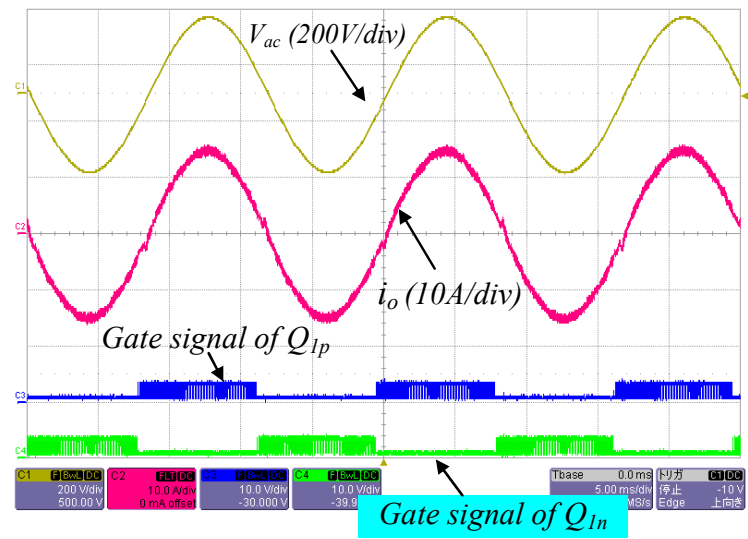

(b) Enlarged waveforms near the zero crossing. Fig. 13. Operation waveforms (Grid voltage, output current and driving signals).

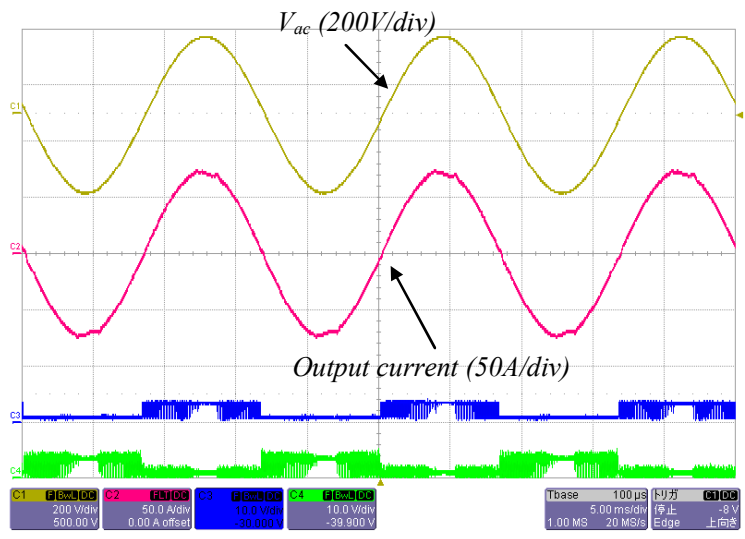

Fig. 14. Output current waveforms.

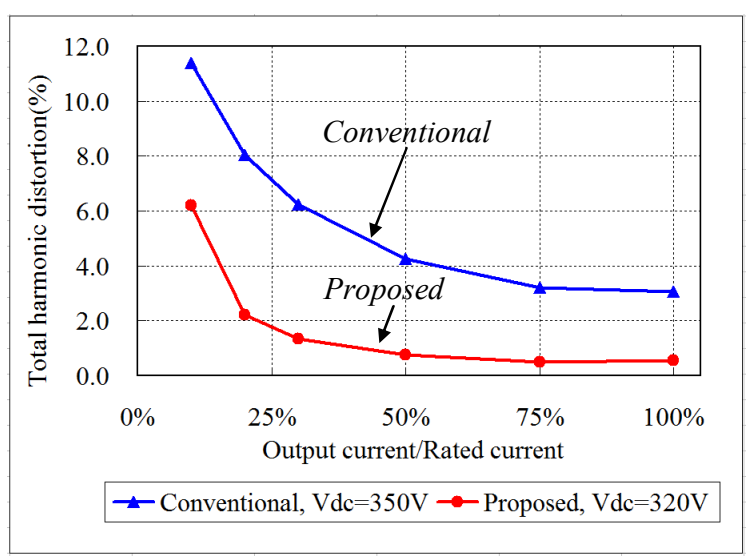

Fig. 15. Total harmonic distortion. 


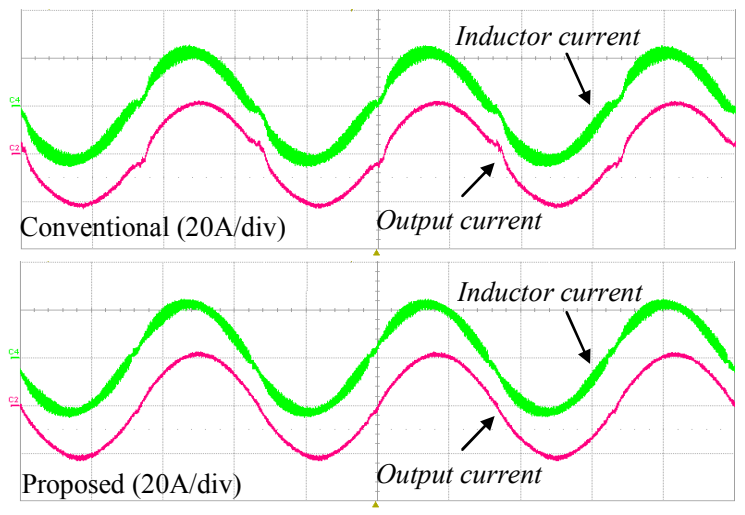

Fig. 16. Inductor current waveforms at $3 \mathrm{~kW}$ output.

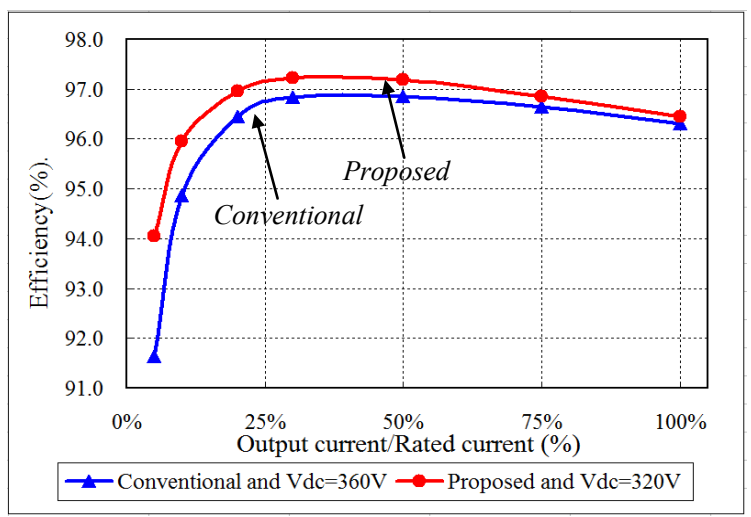

Fig. 18. Improvement in efficiency.

transition between difference control modes. With this control scheme, firstly, the influence of dead-time can be eliminated, and the harmonic distortion can be greatly reduced. Secondly, the dc-link voltage can be minimized that will contribute to a reduced loss and a smaller ripple current. With a low operation voltage, the dc-link capacitor size can be decreased. The proposed control scheme is implemented with a DSP controller, and only some program codes are added. In the experimental system, compared with the conventional control scheme, the following improvements have been achieved.

(1) The total harmonic distortion is decreased to about $1 / 6$ $1 / 3$ of the conventional.

(2) The inductor ripple current is reduced by about $20 \%$. With the same capacitance and a low operation voltage, the capacitor size can be reduced.

(3) An improvement of $0.44 \%$ European efficiency has been confirmed in the experimental inverter circuit.

\section{REFERENCES}

[1] S.B. Kjaer, J.K. Pedersen and F. Blaabjerg,"A Review of SinglePhase Grid-Connected Inverters for Photovoltaic Modules," IEEE Transactions on Industry Applications, vol. 41, no. 5, pp. 1292-1306, Sep./Oct. 2005.

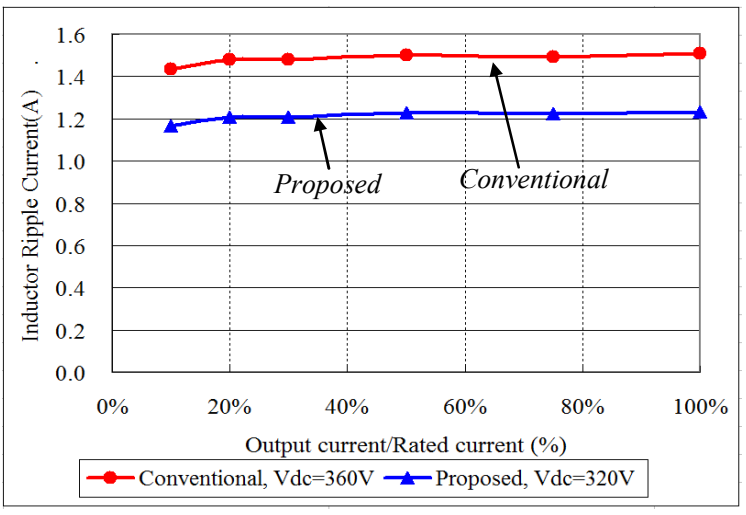

Fig. 17. Inductor switching ripple current.

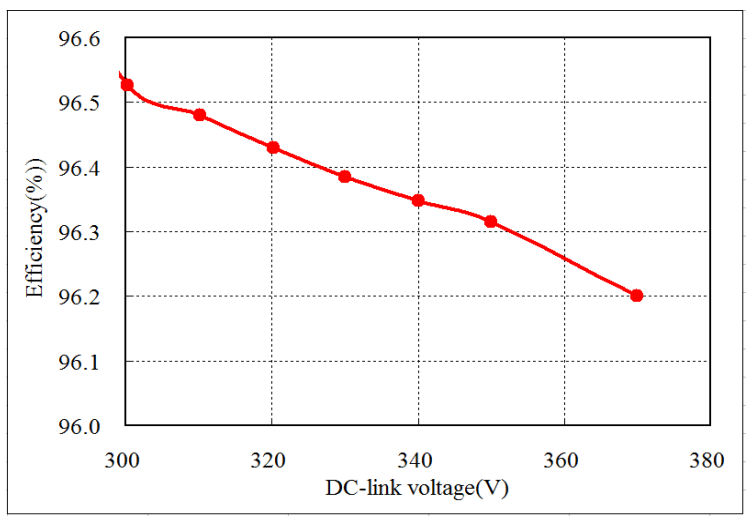

Fig. 19. Efficiency with variations in $V_{d c}$.

[2] M.H. Bierhoff and F.W. Fuchs, "Semiconductor Losses in Voltage Source and Current Source IGBT Converters Based on Analytical Derivation," in Proc. IEEE PESC Record, pp.2836-2842, 2004.

[3] T. Shimizu, K. Ishii, "An Iron Loss Calculating Method for AC Filter Inductors Used on PWM Inverters," in Proc. IEEE PESC Record, pp. 2979-2985, 2006

[4] J.Kang, G.Xu, J.Xu and C.Zhou, "Study of Compensation Method on Dead-time Effects for VSI Fed Drive Systems," IEEE PESC Record, pp.548-552, 2007.

[5] A.R.Munoz, T.A. Lipo, "On-Line Dead Time Compensation Technique for Open-Loop PWM-VSI Drives," IEEE Trans. on Power. Elec. Vol. 14. No. 4. pp. 683-689, 1999.

[6] D. Leggate, R. J. Kerkman, "Pulse Based Dead Time Compensator For PWM Voltage Inverter, " IEEE - Transactions on Industrial Electronics, Vol. 44, No. 2, pp. 191-197, April 1997.

[7] Z. Guo and F. Kurokawa, "A New Hybrid Current Control Scheme for Dead-Time Compensation of Inverters with LC filter," in EPE 2009, Paper 0890.

[8] Z. Guo and F. Kurokawa, "Control and PWM modulation scheme for dead-time compensation of CVCF inverters," in Proc. of INTELEC 2009.

[9] Bowtell, Leslie and Ahfock, Tony L, "Comparison between unipolar and bipolar single phase grid-connected inverters for PV applications," In 17th Australasian Universities Power Engineering Conference (AUPEC'07), 9-12 Dec 2007, Perth, Australia. 